\section{ORIGINAL RESEARCH}

W.J. van Rooij

M. Sluzewski

\title{
Coiling of Very Large and Giant Basilar Tip Aneurysms: Midterm Clinical and Angiographic Results
}

BACKGROUND AND PURPOSE: The purpose of this study was to report the midterm clinical and angiographic results of coiling of very large $(>15 \mathrm{~mm})$ and giant basilar tip aneurysms.

\begin{abstract}
MATERIALS AND METHODS: Between January 1995 and October 2005, 44 very large and giant basilar tip aneurysms in 44 patients were coiled. There were 13 men (30\%) and 31 women (70\%) with a mean age of 51.4 years (median, 51 years; range, 34-72 years). Mean aneurysm size was $19.6 \mathrm{~mm}$ (range, 15-30 mm). Of 44 aneurysms, 33 (75\%) had ruptured. Of 11 unruptured basilar tip aneurysms, 7 were incidentally discovered, 1 was additional to another ruptured aneurysm, and 3 were symptomatic by mass effect.
\end{abstract}

RESULTS: Procedural mortality was $2 / 44$ (4.6\%, 95\% confidence interval $(\mathrm{Cl}), 0.4 \%-16 \%)$ and morbidity $1 / 44(2.3 \%, 95 \% \mathrm{Cl}, 0.01 \%-13 \%)$. Of 33 patients with ruptured aneurysms, mean clinical follow-up was 5.2 years (range, $0.5-11.5$ years). Two patients had a rebleeding from the coiled basilar tip aneurysm leading to death in 1 patient and to dependency in the other patient (annual rebleeding rate, $1.1 \%$ ) One other patient died 2 years later of progressive brain stem compression. Mean angiographic follow-up in 41 of 42 surviving patients was 3.1 years. Nineteen aneurysms reopened and were coiled for a second time. Of these, 9 repeatedly reopened with time and were repeatedly coiled up to 6 times. Additional treatments were without complications.

CONCLUSION: Coiling of very large and giant basilar tip aneurysms is associated with reasonably low morbidity. Although additional treatment during follow-up is frequently necessary, rebleeding is uncommon.

S ince the introduction of detachable coils to treat intracranial aneurysms in the early 1990s, the management of basilar tip aneurysms changed rapidly from surgical to endovascular treatment. The intimate relation of basilar tip aneurysms with critical perforating arteries to the brain stem together with the deep location of these aneurysms makes surgical treatment difficult, resulting in higher surgical morbidity rates than for aneurysms in other locations. This is particularly true for large and giant basilar aneurysms. ${ }^{1-3}$ On the other hand, endosaccular occlusion of basilar tip aneurysms with detachable coils is relatively straightforward and not different from that in aneurysms at other locations. ${ }^{4-10}$ Adjunctive supporting devices (supporting balloon, stent, or TriSpan [Boston Scientific, Fremont, Calif]) may facilitate coiling of wide-necked basilar tip aneurysms. ${ }^{11-13}$

A drawback of coiling is the possibility of reopening of the aneurysmal lumen with time due to compaction of the coil mesh or migration of coils into intraluminal thrombus. Reopening with time after coiling particularly occurs in large and giant aneurysms, and these aneurysms frequently need to be coiled again. ${ }^{14,15}$ Alternative therapies for these large aneurysms with more durable results than coiling, such as direct surgical clipping or parent vessel occlusion when necessary preceded by bypass surgery, may be considered. ${ }^{16,17}$ However, such treatments for large and giant aneurysms on the basilar tip carry substantial morbidity. ${ }^{18,19}$ Therefore, coiling is the

Received October 19, 2006; accepted after revision December 8.

From the Department of Radiology, St. Elisabeth Ziekenhuis, Tilburg, the Netherlands.

Please address correspondence to W.J. van Rooij MD, PhD, Department of Radiology, St. Elisabeth Ziekenhuis, Hilvarenbeekseweg 60, 5022 GC Tilburg, The Netherlands; e-mail: radiol@knmg.nl

DOI 10.3174/ajnr.A0556 preferred treatment for large and giant aneurysms of the basilar tip because of its low morbidity, despite the considerable chance of reopening of the aneurysm with time. In this study, we report the clinical and angiographic results of coiling of 44 very large and giant basilar tip aneurysms coiled in a 12 -year period.

\section{Materials and Methods}

\section{Patients}

Between January 1995 and October 2005, 941 aneurysms were coiled at our institution. Of these, 149 aneurysms (16\%) in 149 patients were located on the basilar tip. Of 149 basilar tip aneurysms, 44 (30\%) were $15 \mathrm{~mm}$ or larger. Thirty-four aneurysms were very large (15-24 mm) and 10 aneurysms were giant $(\geq 25 \mathrm{~mm}$ ). These 44 very large and giant basilar tip aneurysms in 44 patients are the subject of the present study.

There were 13 men (30\%) and 31 women (70\%) with a mean age of 51.4 years (median, 51 years; range, $34-72$ years). Mean size of the basilar tip aneurysms was $19.6 \mathrm{~mm}$ (median, $18 \mathrm{~mm}$; range, 15-30 $\mathrm{mm})$. Of 44 basilar tip aneurysms, 33 (75\%) had ruptured and 11 (25\%) were unruptured. Hunt and Hess ( $\mathrm{HH})$ grade of the 33 patients with ruptured aneurysms was HH 1-2 in 25 (76\%), HH 3 in 4 (12\%), and $\mathrm{HH} 4-5$ in $4(12 \%)$. Timing of treatment after subarachnoid hemorrhage ( $\mathrm{SAH}$ ) was $\leq 7$ days in 20 patients $(61 \%)$ and $>7$ days in 13 patients $(39 \%)$.

Of 11 unruptured basilar tip aneurysms, 7 were incidentally discovered on imaging studies performed for clinical reasons unrelated to the presence of the aneurysm, 1 was found additional to another ruptured aneurysm, and 3 were symptomatic by mass effect on the brain stem. 


\section{Coiling Procedure}

Coiling of aneurysms was performed with the patient under general anesthesia and systemic heparinization. Heparin was continued intravenously or subcutaneously for 48 hours after the procedure, followed by low-dose aspirin for 3 months orally. Coiling was performed with Guglielmi detachable coils (GDC 18; Boston Scientific), 50-cmlong mechanically detachable coils (Detach 18; Cook, Copenhagen, Denmark), or Trufill Orbit coils (Cordis, Miami Lakes, Fla). The aim of coiling was to pack the aneurysm as densely as possible, until not a single additional coil could be placed. Initial angiographic results of coiling were classified as complete occlusion (98\%-100\%), nearcomplete occlusion (90\%-98\%), and incomplete occlusion $(<90 \%)$. Complications of coiling were recorded.

\section{Supporting Devices}

Eleven wide-necked aneurysms were coiled once or more with a temporary supporting balloon (Sentry; Boston Scientific), and 5 widenecked aneurysms were coiled after placement of a permanent supporting device (TriSpan). One aneurysm, initially coiled with aid of a TriSpan, was later retreated after placement of a stent (Neuroform; Boston Scientific).

\section{Follow-Up Schedule}

Patients who survived the hospital admission period were scheduled for clinical follow-up in the outpatient clinic at 6 weeks and for angiographic follow-up at 6 and 18 months. Extended imaging follow-up consisted of angiography or MR angiography (MRA) at 1- to 2-year intervals. Results of angiographic follow-up were classified in the same way as the initial postembolization occlusion. Incomplete occlusion at any point in time was considered an indication for further therapy, unless clinical or anatomic factors dictated otherwise. Clinical follow-up was assessed according to the Glasgow Outcome Score (GOS) at every outpatient clinic visit and at every admission for follow-up angiography. Results and consequences of clinical and angiographic follow-up were discussed in a weekly joint meeting with neuroradiologists, neurosurgeons, and neurologists. When appropriate, during the meeting a decision was made as to the need for additional treatment or extended angiographic follow-up. When additional treatment was performed, the result was evaluated in the weekly meeting, and 6-month follow-up was scheduled.

\section{Rebleeding Rate}

Re-ruptures of aneurysms that presented with SAH were recorded. Annual rebleeding rate was calculated for ruptured aneurysms in patients who survived the hospital admission period.

\section{Results}

\section{Initial Results of Coiling and Complications}

Initial aneurysm occlusion was complete in 22 aneurysms (50\%), near-complete in 15 aneurysms (34\%), and incomplete in 7 aneurysms (26\%). Procedural complications leading to death occurred in 2 patients (mortality, $4.6 \%$; 95\% confidence interval $(\mathrm{CI}), 0.4 \%-16 \%)$ and to permanent disability in 1 patient (morbidity, 2.3\%; 95\% CI, 0.01\%-13\%).

A 52-year-old woman with a $15-\mathrm{mm}$ ruptured basilar tip aneurysm developed thrombosis of the tip of the basilar artery several hours following coiling. Selective intra-arterial urokinase treatment was not effective, and she died 3 days later. In a 59-year-old woman with a 30-mm basilar tip aneurysm symp- tomatic by mass effect, malposition of the guidewire of the supporting balloon during manipulation caused a rupture of a superior cerebellar artery branch, leading to hemorrhage and death.

In a 60 -year-old woman with a 20 -mm ruptured basilar tip aneurysm, malposition of the coils caused a thromboembolic occlusion of the right posterior cerebral artery, leading to occipital and thalamic infarctions. She is in a nursing home.

\section{Clinical Follow-Up}

\section{Patients with Ruptured Aneurysms}

Of 33 patients with ruptured aneurysms, 1 patient died of a procedural complication. Of the 32 surviving patients, mean clinical follow-up was 5.2 years (median, 5.5 years; range, 0.5 11.5 years). Total follow-up in the 32 patients was 2292 months (191 years).

During 191 patient years of follow-up, 2 patients had a rebleeding from the coiled basilar tip aneurysm, leading to death in 1 patient and to dependency in the other patient (annual rebleeding rate $2 / 191 \times 100 \%=1.1 \%$ ). The first patient was a 52-year-old man admitted in 1995 in HH grade 1 after $\mathrm{SAH}$ from a $28-\mathrm{mm}$ basilar tip aneurysm, which was incompletely occluded after coiling due to failure of the electrolytic detachment system (a flaw in the early GDC system). In the following weeks, he developed symptoms of brain stem compression, and occlusion of the basilar artery was considered. Test occlusions of the upper, mid, and lower basilar artery were performed but not tolerated. A bypass from the external carotid artery to the $\mathrm{P} 2$ was constructed followed by occlusion of both vertebral arteries with balloons. This resulted in subtotal occlusion of the aneurysm. Six months later the patient suddenly died, and autopsy disclosed a rebleeding from the basilar tip aneurysm. The second patient was a 73-year-old woman with a ruptured $15-\mathrm{mm}$ basilar tip aneurysm that was coiled and almost completely occluded. She refused 6-month follow-up angiography. Twelve months after coiling, she was re-admitted in another hospital after rebleeding from the coiled aneurysm and referred for additional coiling. On angiography, the aneurysm had enlarged, probably by resolution of intraluminal thrombus, and the coil mesh was displaced and compacted. A second coiling resulted in near-complete occlusion of the aneurysm. She became dependent after the second SAH.

One other patient, a 69 -year-old woman with a $30-\mathrm{mm}$ ruptured basilar tip aneurysm, died 2 years later of progressive brain stem compression by the aneurysm (Fig 1 ). Initially the aneurysm was coiled with a near-complete occlusion. After 6 months, the aneurysm was partially reopened and coiled for a second time. Eighteen months later, she was readmitted with symptoms of brain stem compression, and MR imaging showed an enlargement of the aneurysm caused by intramural dissection and brain stem edema. She died several days later.

Of the remaining 29 patients, 2 patients died of unrelated diseases during follow-up: 1 patient died of pancreatic carcinoma 8.2 years after coiling and another patient died of pneumonia 5.5 years after coiling. Two patients are dependent (GOS 3) as a result of infarctions caused by vasospasm after $\mathrm{SAH}$ and in a nursing home; the other 25 patients are doing well (GOS 4 or 5). 

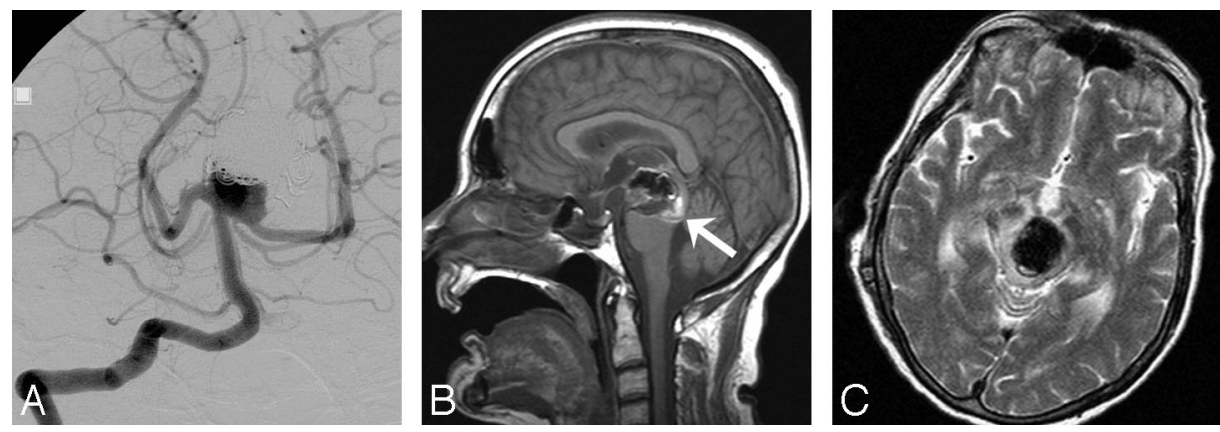

Fig 1. Intramural dissection of a partially occluded giant basilar tip aneurysm in a 69-year-old woman causing fatal brain stem compression.

$A$, Frontal vertebral angiogram 6 months after the second coiling of a 30-mm basilar tip aneurysm demonstrates incomplete occlusion. In view of the wide neck, additional coiling was judged impossible.

$B$, Six months later, she was admitted with sudden onset of symptoms of brain stem compression. Sagittal T1-weighted MR image shows intramural dissection in the posterior part of the aneurysm (arrow), resulting in sudden enlargement and compression on the brain stem.

C, Transverse T2-weighted MR image shows mass effect with brain stem edema, from which she died several days later.

\section{Patients with Unruptured Aneurysms}

Of 11 patients with unruptured aneurysms, 1 patient with an aneurysm symptomatic by mass effect died of a procedural complication. Of the 10 surviving patients, mean clinical follow-up was 2.6 years (median, 1.8 years; range, $0.5-6.5$ years). Of 2 patients with symptoms of brain stem compression, the compression resolved in 1 (GOS 5) and worsened in 1 (GOS 3). The other 8 patients are clinically intact (GOS 5).

\section{Angiographic Follow-Up and Additional Treatments}

Angiographic follow-up was available in 41 of 42 surviving patients. One patient, dependent after SAH and in a nursing home, refused follow-up angiography. Mean angiographic follow-up was 3.1 years (median, 1.9 years; range, 0.5-11.5 years). Of 41 patients, 31 had extended angiographic follow-up beyond the 6-month period. During the follow-up period, 19 aneurysms reopened and were coiled for a second time. Of these, 9 repeatedly reopened with time and were coiled for a third time, fourth time ( 5 aneurysms), fifth time (2 aneurysms), and sixth time (1 aneurysm). All additional coiling was without complication. Altogether, 79 coil treatments were performed in the 44 aneurysms. Reopening was caused by compaction or migration of the coil mesh into intraluminal thrombus in most cases. In 2 aneurysms, local regrowth near the inflow zone became apparent at 89 and 130 months after first coiling (76 and 95 months after the last coiling, respectively).

\section{Discussion}

Very large and giant basilar tip aneurysms form a special subset of intracranial aneurysms that account for $5 \%$ of all coiled intracranial aneurysms in our practice. If left untreated, prognosis is grim. Surgery has long been the only treatment option but is challenging and associated with substantial morbidity. ${ }^{3,4,9}$ The introduction of detachable coils has greatly facilitated the management of basilar tip aneurysms, and coiling has rapidly replaced surgical treatment because coiling of basilar tip aneurysms is technically not different from coiling of aneurysms at other locations without additional associated morbidity. ${ }^{5,8,10,20}$ Nowadays, surgical techniques for large and giant basilar tip aneurysms such as direct clipping under hypothermia with circulatory arrest and bypass surgery ${ }^{18,19}$ are not serious treatment alternatives for coiling in most centers. Nevertheless, because most large and giant basilar tip aneurysms have a wide neck, coiling of these aneurysms may be technically difficult, and supporting devices that prevent coil herniation in the parent artery are frequently needed. Supporting balloons have been available for this purpose since the early 1990s, and later, the TriSpan supporting device and the intracranial stent became available. ${ }^{1-13}$ The use of these supporting devices makes the coiling procedure more complex, resulting in increased morbidity. ${ }^{11}$

Despite the frequent use of supporting devices, in this study, coiling of very large and giant basilar tip aneurysms was associated with low morbidity and mortality, in the same range as for other studies that include basilar tip aneurysms of all sizes. Most patients had good outcomes during up to 11.5years follow-up. Although many aneurysms could not be occluded completely and many aneurysms reopened during follow-up necessitating additional coil treatment, rebleeding from the coiled aneurysm was rare and additional treatments were without complications. The 2 rebleedings in our study probably could have been prevented. In 1 patient, failure of electrolytic detachment of the coils in the presence of multiple other coils precluded adequate aneurysm occlusion in 1995. This problem of early GDC design has been overcome since then. The other patient with a rebleeding had refused 6-month follow-up angiography, and after the rebleeding at 12 months after coiling, angiography showed a 50\% reopening and enlargement of the aneurysm. It is likely that this reopening would have been present at 6 months and additional coiling should then have been performed.

One patient with an incompletely occluded very large basilar tip aneurysm died 2 years after coiling of mass effect on the brain stem after an intramural dissection and enlargement of the aneurysm. Apparently, coiling does not always protect against the occurrence of wall dissections in these large aneurysms.

Large or giant aneurysm size is a well-known risk factor for the occurrence of compaction and reopening because attenuated packing cannot be obtained in these aneurysms. ${ }^{14,15}$ In our series, 19 of 44 aneurysms were additionally coiled once or more during follow-up. This means that coiling of very large and giant basilar tip aneurysms may be considered a staged 
treatment in many patients. However, the treatment strategy of coiling, angiographic follow-up, and additional coiling when necessary is safe and effective in preventing rebleedings. Because late aneurysm regrowth may occur as long as 8 years after apparent complete and stable occlusion, imaging follow-up must be ongoing, even after stable aneurysm occlusion for some years. With the availability of high-resolution MRA, ${ }^{21}$ we now follow-up all patients with coiled large basilar tip aneurysms yearly with MRA instead of angiography.

\section{Conclusion}

Coiling of very large and giant basilar tip aneurysms is associated with reasonably low morbidity. Although long-term angiographic efficacy is poor, a practice of close monitoring and retreatment with coiling when necessary can keep rebleeding rates at levels that are, in our opinion, acceptable, considering the morbidity of other treatment alternatives.

\section{References}

1. Lozier AP, Kim GH, Sciacca RR, et al. Microsurgical treatment of basilar apex aneurysms: perioperative and long-term clinical outcome. Neurosurgery 2004;54:286-96

2. Ogilvy CS, Carter BS. Stratification of outcome for surgically treated unruptured intracranial aneurysms. Neurosurgery 2003;52:82-87

3. Ogilvy CS, Hoh BL, Singer RJ, et al. Clinical and radiographic outcome in the management of posterior circulation aneurysms by use of direct surgical or endovascular techniques. Neurosurgery 2002;51:14-21

4. Lusseveld E, Brilstra EH, Nijssen PC, et al. Endovascular coiling versus neurosurgical clipping in patients with a ruptured basilar tip aneurysm. J Neurol Neurosurg Psychiatry 2002;73:591-93

5. Vallee JN, Aymard A, Vicaut E, et al. Endovascular treatment of basilar tip aneurysms with Guglielmi detachable coils: predictors of immediate and long-term results with multivariate analysis 6-year experience. Radiology 2003;226:867-79

6. Tateshima S, Murayama Y, Gobin YP, et al. Endovascular treatment of basilar tip aneurysms using Guglielmi detachable coils: anatomic and clinical outcomes in 73 patients from a single institution. Neurosurgery 2000;47:1332-39
7. Eskridge JM, Song JK. Endovascular embolization of 150 basilar tip aneurysms with Guglielmi detachable coils: results of the Food and Drug Administration multicenter clinical trial. J Neurosurg 1998;89:81-86

8. Lempert TE, Malek AM, Halbach VV, et al. Endovascular treatment of ruptured posterior circulation cerebral aneurysms: clinical and angiographic outcomes. Stroke 2000;31:100

9. van der Schaaf I, Algra A, Wermer M, et al. Endovascular coiling versus neurosurgical clipping for patients with aneurysmal subarachnoid haemorrhage. Cochrane Database Syst Rev 2005 Oct 19;(4):CD003085

10. Lozier AP, Connolly ES Jr, Lavine SD, et al. Guglielmi detachable coil embolization of posterior circulation aneurysms: a systematic review of the literature. Stroke 2002;33:2509-18

11. Sluzewski M, van Rooij WJ, Beute GN, et al. Balloon-assisted coil embolization of intracranial aneurysms: incidence, complications, and angiography results. J Neurosurg 2006;105:396-99

12. Raymond J, Guilbert F, Roy D. Neck-bridge device for endovascular treatment of wide-neck bifurcation aneurysms: initial experience. Radiology 2001;221:318-26

13. Kis $\mathrm{B}, \mathrm{Weber} \mathrm{W}$, Berlit $\mathrm{P}$, et al. Elective treatment of saccular and broad-necked intracranial aneurysms using a closed-cell nitinol stent (Leo). Neurosurgery 2006;58:443-50

14. Sluzewski M, van Rooij WJ, Slob MJ, et al. Relation between aneurysm volume, packing, and compaction in 145 cerebral aneurysms treated with coils. Radiology 2004;231:653-58

15. Sluzewski M, Menovsky T, van Rooij WJ, et al. Coiling of very large or giant cerebral aneurysms: long-term clinical and serial angiographic results. AJNR Am J Neuroradiol 2003;24:257-62

16. van Rooij WJ, Sluzewski M, Slob MJ, et al. Predictive value of angiographic testing for tolerance to therapeutic occlusion of the carotid artery. AJNR Am J Neuroradiol 2005;26:175-78

17. Jafar JJ, Russell SM, Woo HH. Treatment of giant intracranial aneurysms with saphenous vein extracranial-to-intracranial bypass grafting: indications, operative technique, and results in 29 patients. Neurosurgery 2002;51:138-44

18. Evans JJ, Sekhar LN, Rak R, et al. Bypass grafting and revascularization in the management of posterior circulation aneurysms. Neurosurgery 2004;55:1036-49

19. Sullivan BJ, Sekhar LN, Duong DH, et al. Profound hypothermia and circulatory arrest with skull base approaches for treatment of complex posterior circulation aneurysms. Acta Neurochir (Wien) 1999;141:1-11

20. van Rooij WJ, Sluzewski M, Beute GN, et al. Procedural complications of coiling of ruptured intracranial aneurysms: incidence and risk factors in a consecutive series of 681 patients. AJNR Am J Neuroradiol 2006;27:1498-501

21. Majoie CB, Sprengers ME, van Rooij WJ, et al. MR angiography at $3 T$ versus digital subtraction angiography in the follow-up of intracranial aneurysms treated with detachable coils. AJNR Am J Neuroradiol 2005;26:1349-56 